\title{
A NEW LOOK IN DESIGNING SUSTAINABLE CITY LOGISTICS ROAD PRICING SCHEMES
}

\author{
ARMANDO CARTENI \\ Department of Civil, Construction and Environmental Engineering, \\ University of Naples "Federico II", Italy
}

\begin{abstract}
The congestion caused by freight vehicles within city logistics has become a serious problem for the cities round the world. Furthermore, the pollutant impacts of these vehicles are very high also at urban scale. Many cities are trying to propose planning strategies aimed at reducing these external impact of freight transport through sustainable transport policies. The idea of introducing a toll for rationalize the use of the road infrastructures by freight vehicles in city logistics is one of the most common Transportation Demand Management policies. The development of ITS technologies today allow to design these pricing schemes in several ways connecting the price to individual trips either on the congestion level as well as to the freight vehicle consumptionlemission characteristics or the size and the loading factor. The road-pricing is a well-established practice all round the world. One of the main limits of the available case studies is that they don't take into account the impacts on the acceptance and on equity among the freight carriers. The aim of the study is to propose a new look in designing a sustainable city logistics road pricing schemes based on transport-related "acceptance and equity" measures useful for enlarge both the acceptance of this policy among the carriers and the equity produced in term of transport costs supported by the freight companies competing in the market. The origin-destination net perceived utility $s(\mathbf{V})$ is the variable proposed as an acceptance and equity measure. The idea was to consider the dispersion of $\mathbf{s}(\mathbf{V})$ as a measure of equity and the change in $\mathbf{s}(\mathbf{V})$ deriving from a road-pricing scheme as an inverse measure of acceptance (the smaller the change the larger is the acceptance of the policy among freight carriers). Furthermore, an application to a toy network was performed to test the benefit and the applicability of the proposed measure at reducing external and internal impacts deriving from a city logistics policy.

Keywords: freight transport, urban distribution, transportation planning, decision support system, optimization problem, decision-making process, welfare, quality of life.
\end{abstract}

\section{INTRODUCTION}

A sustainable city is composed of three pillars: environment, society and economy and must be, at the same time, viable, equitable and bearable. Within this vision, transportation system cover an important role in sustainable city, because of its impacts (external costs) in environmental emissions and quality of life. Many cities are adopting planning policies aimed at reducing external costs deriving from transport sector, through the implementation of rational planning policies (e.g. Cascetta et al. [1]) based on sustainability (e.g. Cartenì [2]). Among these policies, the road pricing is one of the most useful ones. The road pricing is based on the introduction of a toll (pricing) for the use of a road infrastructure at urban scale. This policy is a well-established practice round the world as demonstrate by the copious state of the art on this topic (e.g. Cools et al. [3]; De Palma et al. [4]; Ecola and Light [5]; Ferrari [6]; Grisolía et al. [7]; Levinson [8]; Kim et al. [9]; May et al. [10]; Odeck and Kjerkreit [11]; Verhoef and Rouwendal [12]; Viegas [13]). The road pricing schemes could be grouped into:

- $\quad$ toll pricing, for which vehicles pay for using a road infrastructure;

- cordon/area pricing, for which the vehicles pay for entering in a restricted area of a city (e.g. an Historical area in the city centre). 
With respect to city logistics, the development of the Intelligent Transportation System (ITS) technologies allow today to design pricing schemes in a most sustainable ways, for example, linking the toll both to the characteristics of the trip and to the type of freight vehicle used for the urban distribution, as for example:

- distance-based toll, where the price is (directly) function of the trip distance;

- time-based toll, where the price is function of peak and off-peak hours of the day, or the seasons within the year (e.g. summer and winter months);

- congestion-based toll, where the price is function of the congestion level of the network;

- vehicle-based toll, where the price is function of the freight vehicle typology. Different tolls could be defined according to both the environmental impact of the vehicle (e.g. electric vehicle vs. traditional vehicle; old vehicle vs. new vehicle, light goods vehicle vs. heavy goods vehicle) and the loading factor (e.g. $0-30 \%$ of vehicle loading factor, $30-60 \%$ of vehicle loading factor, $>60 \%$ of vehicle loading factor).

Among the examples of applied freight (and passengers) road-pricing schemes there are: Singapore (cordon, time peak/off-peak hours, distance of the trip and vehicle-based); London UK (cordon and time-Based); Milan Italy (cordon, time and Vehicle-based); New York USA (bridge/tunnel crossing and time-based). Singapore is probably the oldest case study, based on a "pay-as-you-use" congestion cordon pricing scheme (e.g. Goh [14]; Phang and Rex [15]; Seik [16]). London proposes a time-based cordon pricing scheme (e.g. Beevers and Carslaw [17]; Santos and Fraser [18]; Santos and Bhakar [19]), while Milan has introduced in 2008 a time and vehicle-based cordon pricing scheme (e.g. Percoco [20]; Danielis et al. [21]).

All the available case studies aim in reducing vehicles usage and their external costs. Unfortunately, the number of applications of road pricing schemes is definitely lower than its potential benefits due to the consensus difficulties in introducing it (acceptance). Furthermore, in the design of these policy the impact on equity (among the involved users/companies/carriers) is not taken into account. Equity is related with the distribution of benefits/costs among users/companies/carriers. Such benefits/costs (and their variation with respect to a design scenario) can be distributed in an acceptable (or not) way among the users, depending on different criteria. According to the economists, equity (and its variations) could be measured through welfare-based measures based on microeconomic theory. By contrast, according to the transportation planners' equity could be measured through transportation accessibility indicators (measures). Some authors (e.g. Cascetta et al. [22]) propose to consider both a horizontal and a vertical equity. The horizontal equity means how users from a same group (e.g. different type of the companies, carriers with low transport accessibility) fare relative to one another. As proposed by Ecola and Light [5], all people in a group are equal and should benefit equal opportunities (e.g. activities and services). For example, all the carriers operating in a city, pay the same toll $/ \mathrm{km}$. By contrast, vertical equity refers to the distribution of benefits/costs across groups (Ecola and Light [5]) and measure the differences between groups with respect to their ability to pay (e.g. company's income; transportation accessibility/opportunities).

As said, with respect to the acceptance related to a road pricing policy, the current case studies are often followed by a very low consensus, that sometime produce barriers and protests of the freight companies and carriers against the administrations, up to obtain its abrogation (there are many failures all around the world). The difficulties in decision-making processes at urban scale has long been recognized in literature, together with the need to 
"open up" such decision-making processes toward the "consensus buildings" on city logistics policies. To increase the acceptance in a freight policy it could be performed a Public Engagement - PE (or Stakeholder Engagement - SE), that is the process of involving stakeholder concerns, needs and values in the urban planning decision-making process. As defined in Cascetta et al. [1], PE is a two-way communication process that provides a strategy for exchanging information and promoting stakeholder interaction with decision-makers and the design team. The aim of engagement is to achieve a planning process with greater input from stakeholders and their support for the decisions that are taken.

The aim of this paper is to propose and apply an original transport-related "acceptance and equity" indicator (measure) useful for enlarge both the acceptance and the equity (in term of impacts produced on the freight companies and carriers) in the design of a freight road pricing scheme.

\section{AN “ACCEPTANCE AND EQUITY” INDICATOR FOR DESIGN URBAN FREIGHT ROAD PRICING SCHEMES}

According to the RUM (Random Utility Models), in a transport decision context, a decisionmaker (e.g. a carrier or a freight company) assigns to each alternative $\mathrm{j}$ in his/her choice set (e.g. the paths to follow within a distribution channel) a perceived utility $U_{j}$ (where $\mathbf{U}$ is the vector of all the $U_{j}$ perceived utility in the choice set) and choose the alternative that maximizes this utility. $U_{j}$ can be expressed as the sum of a systematic utility $V_{j}(\mathbf{V}$ is the vector of all the $\mathrm{V}_{\mathrm{j}}$ ) and a random residual $\varepsilon . \mathrm{V}_{\mathrm{j}}$ estimate the mean perceived utility (e.g. relative to a path $\mathrm{j}$ ) by all carriers (users) having the same choice (e.g. the same alternatives and attributes). The random residual $\varepsilon$ is the unknown deviation of $U_{j}$ by a generic carrier from this mean value and estimate the joined effects of all the factors that introduce uncertainty into the choice context.

The OD Origin-Destination net perceived utility is the measure proposed as an "acceptance and equity" indicator. In RUM, the EMPU (Expected Maximum Perceived Utility) variable $s(\mathbf{V})$ related to an OD pair could be considered as an estimation of the OD net perceived utility (surplus):

$$
\mathrm{s}=\mathrm{s}(\mathbf{V})=\mathrm{E}\left[\max _{\mathrm{j}}(\mathbf{U})\right]=\mathrm{E}\left[\max _{\mathrm{j}}(\mathbf{V}+\boldsymbol{\varepsilon})\right],
$$

Choosing a ML Multinomial Logit model (and this is the case of the proposed case study), the EMPU measure have a simple and closed form (e.g. Cascetta [23]):

$$
\mathrm{s}(\mathbf{V})=\theta \ln \Sigma_{\mathrm{j}} \exp \left(\mathrm{V}_{\mathrm{j}} / \theta\right)
$$

where $\theta$ is the Gumbel variable parameter. The $s(\mathbf{V})$ proposed "acceptance and equity" is also a transport-related accessibility measure (e.g. Cartenì [24] and Cascetta et al. [25]) because increasing the impedance (e.g. trip distance/time/cost), decrease $\mathrm{s}(\mathbf{V})$, and increasing the number of opportunities (e.g. paths, freight services) increase $s(\mathbf{V})$. The proposed measure (2) is a useful instrument to design road pricing schemes increasing both equity and acceptance among carriers/companies for city logistics (Fig. 1):

- $\quad$ equity impact: the dispersion of $s(\mathbf{V})$ (e.g. the Mean Absolute Deviation - MAD) is a measure of equity with respect to transport accessibility. This means that pricing the OD pairs with more opportunities (e.g. paths for urban freight distribution), generally decrease the $\mathrm{s}(\mathbf{V})$ dispersion (e.g. Fig. 1) and so increases equity (if all the 
carriers/companies support the same $\mathbf{s}(\mathbf{V})$ value, this means that the dispersion is null and so the equity is the highest);

- $\quad$ acceptance impact: the absolute change in OD EMPU $s(\mathbf{V})$ indicators produced by a freight road-pricing scheme is an inverse measure of acceptance, in the sense that the smaller is the change, the larger is the acceptance among the carriers of the policy. Generally, also in this case, pricing OD pairs with more opportunities (e.g. paths), produce a lower (absolute) increase in $s(\mathbf{V})$, and this probably enlarge the acceptability of the road pricing scheme.

To better understand the acceptance and equity implication of the proposed measure, see the example in Fig. 1. As showed, the carriers better tolerate (more consensus and less barriers) a scenario in which the toll is imposed in one of the two paths available within the $\mathrm{OD}_{2}$ pair (and this enlarge also the equity from a transport-related point of view as defined before), while the opposite occurs pricing the unique path connecting the $\mathrm{OD}_{1}$ pair (no price-free path alternatives available for the carriers to reach the destination 1).

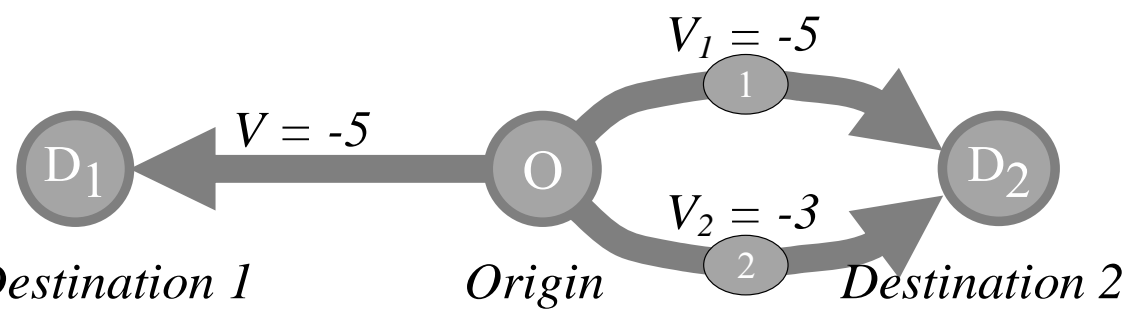

Base scenario: $\mathrm{MAD}=1.06$

Scenario 1: pricing path 2 of the $\mathrm{OD}_{2}$ (2 alternatives) $\Delta V_{2}=-3=\beta \cdot$ cost $_{\text {pricing path } 2} \rightarrow \mathrm{MAD}_{1}=0.16-\mathbf{8 5 \%}$ $\left|\Delta s_{1}\right|=0 \quad\left|\Delta s_{2}\right|=\underbrace{\mathbf{1 . 8}}_{\begin{array}{c}\uparrow \\ \text { more acceptance }\end{array}}$

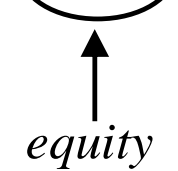

Scenario 2: pricing path of the $O D_{1}(1$ alternative $)$ $\Delta V=-3=\beta \cdot$ cost $_{\text {pricing path }} \rightarrow \mathrm{MAD}_{2}=2.56+\mathbf{1 4 1 \%}$ $\left|\Delta s_{1}\right|=s_{2} \mid=0$

less acceptance non equity

Figure 1: Acceptance and equity impacts in designing a road pricing scheme through the EMPU variable $\mathrm{s}(\mathbf{V})$ measure. 


\section{APPLICATION TO A TOY NETWORK}

The proposed $\mathrm{s}(\mathbf{V})$ "acceptance and equity" indicator was applied as a design variable for an urban freight road pricing scheme. A toy network (reported in Fig. 2 and Table 1) was used to test the applicability of the proposed variable and to better understand its potentially in increasing acceptance and equity of a sustainable transport policy.

Different path-based pricing schemes, aimed at increasing the city sustainability (e.g. reducing pollutant emissions and/or traffic congestion), were tested.

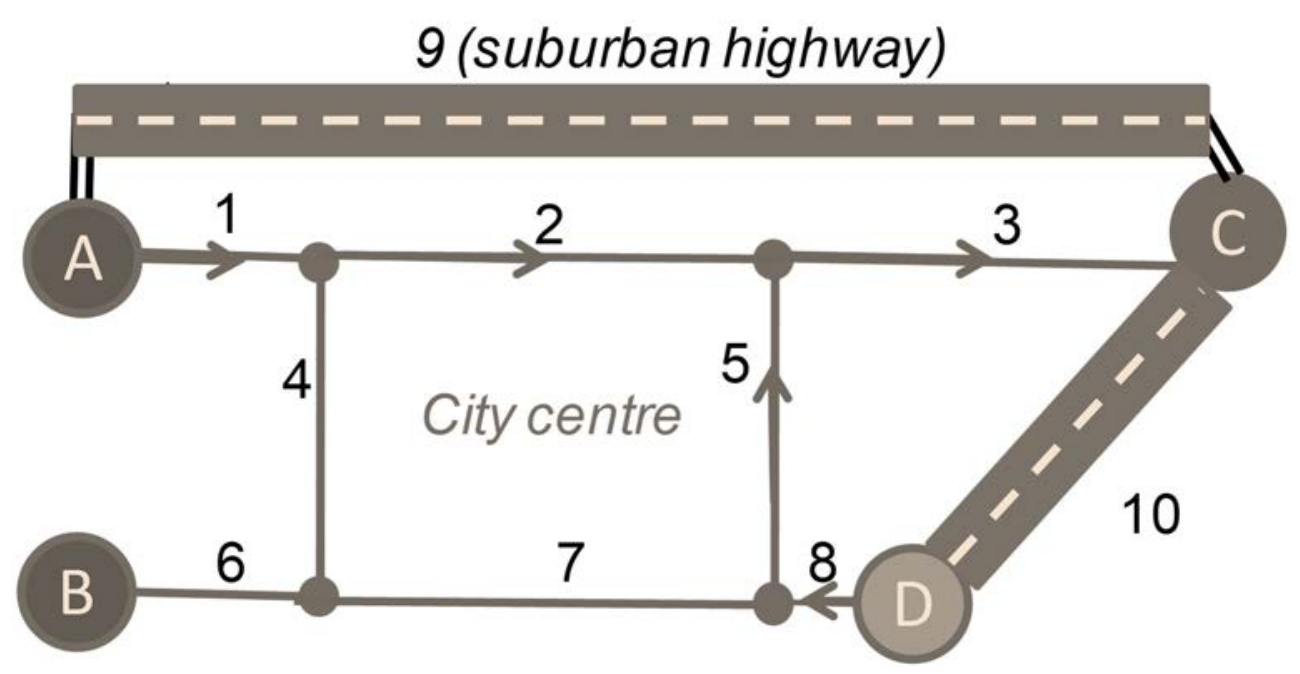

Figure 2: The toy network used in the application case study.

Table 1: The toy network characteristics.

\begin{tabular}{|c|c|c|c|c|c|}
\hline $\begin{array}{l}\text { OD } \\
\text { pairs }\end{array}$ & & Urban Path & $\begin{array}{l}\text { Urban } \\
\text { Road } \\
\text { links }\end{array}$ & $\begin{array}{c}\text { Urban paths } \\
\text { lengths } \\
(\mathrm{km})\end{array}$ & $\begin{array}{c}\text { Alternatives } \\
\text { (urban/ } \\
\text { suburban) }\end{array}$ \\
\hline \multirow{2}{*}{$\mathrm{A}-\mathrm{C}$} & 1 & $\bullet \bullet \bullet \bullet$ & $1,2,3$ & 10 & \multirow{2}{*}{$\begin{array}{c}\text { Urban }+ \\
\text { suburban paths }\end{array}$} \\
\hline & 2 & i. & $1,4,7,5,3$ & 18 & \\
\hline \multirow{2}{*}{$\mathrm{B}-\mathrm{C}$} & 3 & & $6,4,2,3$ & 16 & \multirow{2}{*}{$\begin{array}{l}\text { Urban } \\
\text { paths }\end{array}$} \\
\hline & 4 & 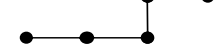 & $6,7,5,3$ & 10 & \\
\hline $\mathrm{D}-\mathrm{C}$ & 5 & $\stackrel{\bullet}{\bullet}$ & $8,5,3$ & 7 & $\begin{array}{c}\text { Urban }+ \\
\text { suburban paths }\end{array}$ \\
\hline D-B & 6 & $\bullet \bullet$ & $8,7,6$ & 6 & $\begin{array}{l}\text { Urban } \\
\text { path }\end{array}$ \\
\hline
\end{tabular}


Jointly with the toy network reported before, both a demand and an assignment models were applied to the case study proposed. The overall transportation system model consist in a within-day static models with variable demand (Fig. 3):

- urban impedance function (supply model) was considered as suggested in Cartenì and Punzo [26], where the link generalized transport cost is equal to the sum of the trip travel time (in a congested network with a pre-load of a private car OD demand) plus the fuel cost (estimated considering 0.15 Euro cent $/ \mathrm{km}$ ). Furthermore, for the suburban highway was considered a ticket price equal to 1.0 Euro/trip;

- a nested Logit demand model as proposed in Cartenì and Russo [27] and Russo and Cartenì [28] for city logistics and in Bifulco et al. [29], hypothesizing an origindestination freight demand flow equal to 1,000 light good vehicles/hour for all the OD pairs;

- an elastic SUE (Stochastic User Equilibrium) supply-demand (assignment) model for congested network as suggested in Cantarella et al. [30].

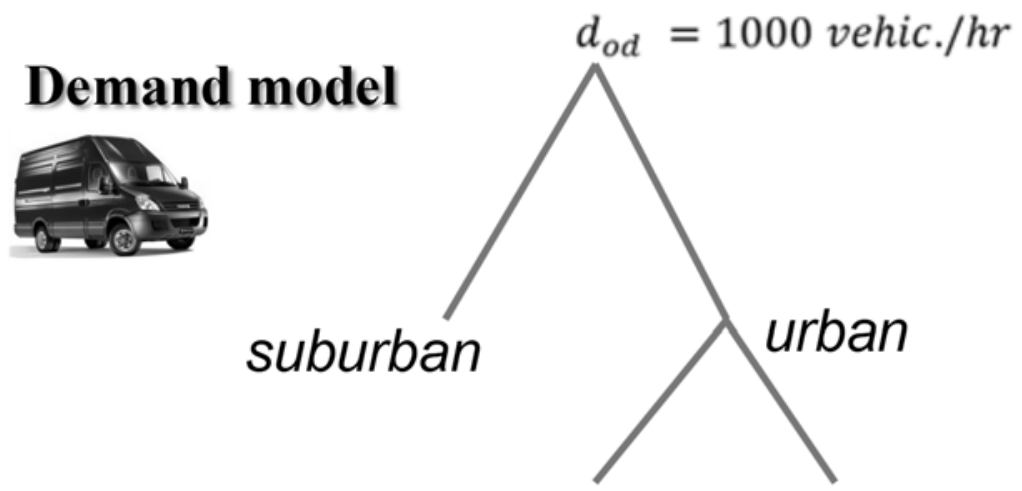

\begin{tabular}{|c|c|c|}
\hline model & attributes & parameter \\
\hline $\begin{array}{l}\text { suburban vs. } \\
\text { urban path }\end{array}$ & $\begin{array}{l}\text { suburban } \\
\text { In-vehicle travel time } \\
\text { Fare } \\
\text { Alt. Specific Constant } \\
\text { urban } \\
\text { Logsum }_{\text {paths }} \\
\end{array}$ & $\begin{array}{l}-1.8(1 / \mathrm{h}) \\
-0.12(1 / €) \\
+0.20 \\
0.85\end{array}$ \\
\hline $\begin{array}{c}\text { Urban Path } \\
\text { choice }\end{array}$ & $\begin{array}{l}\text { Travel time } \\
\text { Monetary Cost }\end{array}$ & $\begin{array}{l}-1.8(1 / \mathrm{h}) \\
-0.12(1 / €)\end{array}$ \\
\hline
\end{tabular}

Figure 3: The city logistics demand model. 
The proposed constrained optimization road pricing problem was:

where:

$$
\mathbf{P}^{*}=\underset{\frac{\mathrm{P}_{\text {toll, } \mathrm{j}} \mathrm{P}_{0, \mathrm{j}}}{\mathrm{P}_{0, \mathrm{i}}}<1.0}{\operatorname{argmin}}\left(\sum_{\mathrm{j}} \mathrm{TT}_{\mathrm{j}}\right)
$$

- $\quad \mathrm{P}^{*}$ is the vector solution of the optimization problem representative of the freight path tolls (6 tolls values for the 6 freight vehicles paths in the network as reported in Tab. 1);

- $\quad P 0, \mathrm{j}$ is the no-project (base) fuel cost relative to the path $\mathrm{j}$ without any road pricing schemes;

- Ptoll, $\mathrm{j}$ is the total monetary cost relative to the path $\mathrm{j}$ (equal to the fuel cost plus the toll result of the optimization problem);

- $\quad$ a constraint was introduced, (Ptoll, $\mathrm{j} / \mathrm{P} 0, \mathrm{j}) / \mathrm{P} 0, \mathrm{j}<1.0$, imposing that the path $\mathrm{j}$ cost increase is always lower than $100 \%$ for all the paths;

- $\quad T T j=$ Tmpj hj, is the Total Travel time of the freight path $\mathrm{j}$, where Tmpj is the average trip travel time relative to the path $\mathrm{j}$ and $\mathrm{hj}$ is the freight demand flow that choose the path $\mathrm{j}$ (result of the assignment model);

- $\quad \quad \quad \mathrm{i} \mathrm{TT} \mathrm{j}$ is the total network trip Travel Time.

Similar results were also obtained with other "traditional" constrained optimization problem (e.g. minimizing the network congestion level or the total pollutant emission caused by the freight vehicles), not reported in the paper for brevity.

Generally, defined the design criteria (e.g. minimizing the total travel time), there are multiple (equivalent) problem (3) solutions (in term of price vectors $\mathbf{P}^{*}$ ). For this reason, was needed to define evaluation criteria for choosing the "best" solution to implement. Among the "traditional" criteria there are, for example, the minimization of:

- environmental emission caused by the freight vehicles;

- overall traffic congestion;

- network Total Generalized Transport Cost (TGTC):

where:

$$
\text { TGTC }=\Sigma_{\mathrm{j}}\left(\text { VTTS } \cdot \text { Time }_{\mathrm{j}}+\text { Cost }_{\mathrm{j}}\right) \cdot \mathrm{h}_{\mathrm{j}}[\text { Euro }]
$$

o VTTS is the Value of the Travel Time Saved (e.g. Cartenì et al. [31]);

o Time $\mathrm{j}$ is the average trip travel time on the freight path $\mathrm{j}$;

o $\quad$ Cost $_{\mathrm{j}}$ is the total freight monetary cost (fuel and toll) on the path $\mathrm{j}$;

o $h_{j}$ is the freight demand flow on the path $\mathrm{j}$.

The indicators proposed to measure the equity and the acceptance of a road pricing policy were:

$$
\begin{array}{cc}
\text { Equity: } & -\left(\mathrm{MAD}^{\text {toll }}-\mathrm{MAD}^{0}\right) / \mathrm{MAD}^{0} \\
& \mathrm{MAD}^{\text {toll }}=\Sigma_{\mathrm{i}}\left|\mathrm{s}_{\mathrm{i}}^{\text {toll }}-\mathrm{s}^{\text {toll }}\right| / \mathrm{N}_{\mathrm{OD}} \\
& \mathrm{MAD}^{0}=\Sigma_{\mathrm{i}}\left|\mathrm{s}_{\mathrm{i}}^{0}-\mathrm{s}^{0}\right| / \mathrm{N}_{\mathrm{OD}} \\
\text { Acceptance: } & \Delta \mathrm{s}=\Sigma_{\mathrm{i}}\left|\mathrm{si}_{\mathrm{i}}^{\text {toll }}-\mathrm{s}_{\mathrm{i}}^{0}\right| / \mathrm{N}_{\mathrm{OD}}
\end{array}
$$


where:

- $\quad$ si0 is the "acceptance and equity" indicator relative to the OD pair i and to the noproject (base) scenario (no road pricing scheme), results of the the eqn (2);

- sitoll is the "acceptance and equity" indicator relative to the OD pair $i$ and to the toll scenario (result of the optimization problem), results of the eqn (2);

- NOD is the number of the origin-destination pairs $\mathrm{c}$ in the toy network proposed;

- $\quad$ stoll $=\Sigma \mathrm{i}$ sitoll/ NOD is the average network "acceptance and equity" indicator value result of the optimization problem.

- $\quad \mathrm{s} 0=\Sigma \mathrm{i}$ si0/ NOD is the average network "acceptance and equity" indicator value relative to the no-project scenario.

Because of, as said before, the optimization problem (3) produce multiple solution (in term of price vectors $\mathbf{P}^{*}$ ) it needs to define one (or more) evaluation criteria for choosing the "best" solution to implement. Using only one (or more) among the "traditional" criteria (e.g. minimization of environmental emission and/or traffic congestion and/or total generalized transport cost) it is possible to choose a solution which produces a decrease in equity and / or is less acceptable among the carriers/freight company. To understand this, it is possible to compare some of the solutions of the optimization problem (3) reported in Table 2. Considering, for example, as a unique criteria to choose the solution to implement the minimization of TGTC, it would be induced to choose the solution number 10 (that produce an increase of $+8 \%$ of TGTC) which significantly increase the inequity among the transport carriers/freight companies (-88\%).

However, considering a "cap and price" strategy, for example, capping (constraining) the TGTC maximum percentage variation to $30 \%$, and using the proposed "acceptance and equity" indicator as an additional (not alternative but integrative) criterion for choosing the solution to implement, it would be possible to choose the solution number 5 or 7 in function of the relevance (in weight) awarded to the equity and to the acceptance criteria. For these solutions, even the TGTC increases of a $21 \%$ and $19 \%$ respectively, both the equity $(+61 \%$ and $+32 \%$ ) and the acceptance (absolute $\Delta$ s between 0.33 and 0.33 ) significantly will increase implementing the road pricing schemes obtained.

\section{CONCLUSION AND FUTURE RESEARCHES}

The aim of this research was to propose an original transport-related "acceptance and equity" variable useful for enlarge both the acceptance and the equity (in term of impacts produced in urban freight distribution) in the design of an urban freight road pricing scheme.

Results of the application underline how the proposed indicator could enlarge both the acceptance and the equity if used as an additional criteria for choosing the "most satisfying" (among multiple solutions) solution to implement.

Among the research perspective:

- apply and compare the proposed indicator in different pricing scheme (e.g. linkbased and OD-based);

- $\quad$ apply the proposed methodology to a real case application (e.g. a medium-size city in Italy);

- extend the proposed "acceptance and equity" measure also to the non-users of the transportation system aiming to perform a sustainable city improving the overall quality of life in an urban context. 
Table 2: Solutions of the optimization problem (3): freight vehicles path pricing tolls; percentage variation (respect the no-project scenario) of the TGTC and MAD (as measure of equity); absolute change in OD "acceptance and equity" $\mathrm{s}(\mathbf{V})$ variable (as measure of acceptance).

\begin{tabular}{|c|c|c|c|c|c|c|c|c|c|c|}
\hline \multirow[b]{2}{*}{$\begin{array}{ll} & \text { Id. } \\
\text { Path } & \\
\end{array}$} & \multicolumn{10}{|c|}{ Solutions of the optimization problem (3) [10*Euro] } \\
\hline & 1 & 2 & 3 & 4 & 5 & 6 & 7 & 8 & 9 & 10 \\
\hline 1 & 1.1 & 0.3 & $\mathbf{0}$ & 0.3 & 0.5 & 0.2 & $\mathbf{0 . 3}$ & 0.2 & 0.3 & 38 \\
\hline 2 & 13 & 7.2 & 2.3 & 2.4 & 1.4 & 12 & 13 & 13 & 13 & 0.6 \\
\hline 3 & 2.3 & 1.6 & 2.3 & 1.3 & 1.2 & 1.6 & 1.4 & 1.6 & 1.6 & 41 \\
\hline 4 & 0.8 & 0.2 & 0 & 0 & 0 & 0 & 0 & 0 & 0 & 0 \\
\hline 5 & 1.6 & 1.5 & 1.6 & 1.1 & 1.2 & 1.5 & 1.5 & 1.7 & 1.5 & 0 \\
\hline 6 & 0.6 & 0.7 & 0.5 & 0.5 & 0.5 & 0.3 & 0.3 & 0.3 & 0 & 0 \\
\hline $\begin{array}{l}\text { TGCT } \\
\% \text { var. }\end{array}$ & 49 & 32 & 20 & 22 & 21 & 19 & 19 & 16 & 10 & 8 \\
\hline $\begin{array}{l}\text {-MAD } \\
\% \text { var. } \\
\text { (equity) }\end{array}$ & -82 & -46 & -13 & 15 & 61 & -7 & 32 & 3 & -27 & -88 \\
\hline $\begin{array}{l}10^{*} \Delta \mathrm{s} \\
\text { (accept.) }\end{array}$ & 5.8 & 4.5 & 4.1 & 3.5 & 3.3 & 3.6 & 3.3 & 3.5 & 3.2 & 3.6 \\
\hline $\begin{array}{l}\text { Dominate } \\
\mathrm{d} \\
\text { solution }\end{array}$ & $\begin{array}{l}\mathrm{YE} \\
\mathrm{S}\end{array}$ & $\begin{array}{c}\mathrm{YE} \\
\mathrm{S}\end{array}$ & NO & $\begin{array}{l}\text { YE } \\
\mathrm{S}\end{array}$ & NO & $\begin{array}{l}\mathrm{YE} \\
\mathrm{S}\end{array}$ & NO & NO & NO & NO \\
\hline $\begin{array}{l}\text { Satisfying } \\
\text { solutions }\end{array}$ & & & & & $\begin{array}{c}\text { YE } \\
\mathbf{S}\end{array}$ & & $\begin{array}{c}\text { YE } \\
\mathbf{S}\end{array}$ & & & \\
\hline
\end{tabular}

\section{REFERENCES}

[1] Cascetta, E., Cartenì, E., Pagliara, F. \& Montanino, M., A new look at planning and designing transportation systems: a decision-making model based on cognitive rationality, stakeholder engagement and quantitative methods, Transport Policy, 38, pp. 27-39, 2015.

[2] Cartenì, A., Urban sustainable mobility, Part 1: Rationality in transport planning. Transport Problems, 9(4), pp. 39-48, 2014.

[3] Cools, M., Brijs, K., Tormans, H., Moons, E., Janssens, D. \& Wets G., The sociocognitive links between road pricing acceptability and changes in travel behaviour, Transportation Research Part A, 45, pp. 779-788, 2011.

[4] De Palma, A., Kilanin, M. \& Lindsey, M., Maintenance, service quality and congestion pricing with competing roads, Transportation Research Part B, 41(5), pp. 573-591, 2007. 
[5] Ecola, E. \& Light, T., Equity and Congestion Pricing: A Review of the Evidence, Rand Corporation, 2010.

[6] Ferrari, P., Road pricing and users' surplus, Transport Policy, 12, pp. 477-487, 2005.

[7] Grisolía, J.M., López, F. \& Ortúzar, J.D., Increasing the acceptability of a congestion charging scheme, Transport Policy, 2015.

[8] Levinson, D., Equity effects of road pricing: are view, Transp. Rev. 30, pp. 33-57, 2010.

[9] Kim, J., Schmöcker, J.D., Fuji, S. \& Noland, R.B., Attitudes towards road pricing and environmental taxation among US and UK students, Transportation Research Part A, 48, pp. 50-62, 2013.

[10] May, A., Koh, A., Blackledge, D. \& Fioretto, M., Overcoming the barriers to implementing urban road user charging schemes, Eur. Transp. Res. Rev., 2, 2010.

[11] Odeck J. \& Kjerkreit, A., Evidence on users'attitudes towards road user chargesacross-sectional survey of six Norwegian toll schemes, Transport Policy, 17, pp. 349$358,2010$.

[12] Verhoef, E.T. \& Rouwendal, J., Pricing, capacity choice, and financing in transportation networks, Journal of Regional Science, 44(3), pp. 405-435, 2004.

[13] Viegas, J.M., Making urban road pricing acceptable and effective: Searching for quality and equity in urban mobility, Transport Policy, 8(4), pp. 289-294, 2001.

[14] Goh, M., Congestion management and electronic road pricing in Singapore, Journal of Transport Geography, 10(1), pp. 29-38, 2002.

[15] Phang, S.Y. \& Rex, S.T., From manual to electronic road congestion pricing: The Singapore experience and experiment, Transportation Research Part E, 33(2), pp. 97106, 1997.

[16] Seik, F.T., An advanced demand management instrument in urban transport: Electronic road pricing in Singapore, Cities, 17(1), pp. 33-45, 2000.

[17] Beevers, S.D. \& Carslaw, D.C., The impact of congestion charging on vehicle emissions in London, Atmospheric Environment, 39(1), pp. 1-5, 2005.

[18] Santos, G. \& Fraser, G., Road pricing: lessons from London; Economic Policy, 21(46), pp. 264-310, 2006.

[19] Santos, G. \& Bhakar, J., The impact of the London congestion charging scheme on the generalised cost of car commuters to the city of London from a value of travel time savings perspective, Transport Policy, 13(1), pp. 22-33, 2006.

[20] Percoco, M., The impact of road pricing on housing prices: Preliminary evidence from Milan, Transportation Research Part A, Policy \& Practice, 67, pp. 188-194, 2014.

[21] Danielis, R., Rotaris, L., Marcucci, E. \& Massiani, J., A medium term evaluation of the ecopass road pricing scheme in Milan: Economic, environmental and transport impacts [Una valutazione intermedia del modello di road pricing ecopass a Milano: Gli impatti economici, ambientali e sul trasporto, Economics and Policy of Energy and the Environment, (2), pp. 49-83, 2012.

[22] Cascetta, E., Cartenì A. \& Henke, I., Acceptance and equity in advanced path-related road pricing schemes, Proceedings of 5th IEEE International Conference on Models and Technologies for Intelligent Transportation Systems, Naples, Italy, 2017.

[23] Cascetta, E., Transportation System Analysis: Models and Applications, Springer, New York, 2009.

[24] Cartenì, A., Accessibility indicators for freight transport terminals, Arabian Journal for Science and Engineering, 39(11), pp. 7647-7660, 2014. 
[25] Cascetta, E., Cartenì, A. \& Montanino, M., A behavioral model of accessibility based on the number of available opportunities, Journal of Transport Geography 51, pp. 45$58,2016$.

[26] Cartenì, A. \& Punzo, V., Travel time cost functions for urban roads: A case study in Italy, WIT Transactions on the Built Environment, 96, pp. 233-243, 2007.

[27] Cartenì, A. \& Russo, F., A distribution regional freight demand model, Advances in Transport, 16, pp. 275-285, 2004.

[28] Russo, F. \& Cartenì, A., Application of a tour-based model to simulate freight distribution in a large urbanized area, in Recent Advances in City Logistics: Proceedings of the 4th International Conference on City Logistics, Langkawi, Malaysia, Elsevier B.V., Kidlington, UK, pp. 31-46, 2006.

[29] Bifulco, G.N., Cartenì, A. \& Papola, A., An activity-based approach for complex travel behaviour modeling, European Transport Research Review, 2(4), pp. 209-221, 2010.

[30] Cantarella, G.E., de Luca, S. \& Cartenì, A., Stochastic equilibrium assignment with variable demand: theoretical and implementation issues, European Journal of Operational Research, 241(2), pp. 330-347, 2015.

[31] Cartenì, A., Cascetta, E. \& de Luca, S., A random utility model for park \& carsharing services and the pure preference for electric vehicles, Transport Policy, 48, pp. 49-59, 2016. 